\title{
Intravital microscopy reveals endothelial dysfunction in resistance arterioles in Angiotensin II-induced hypertension
}

\author{
Stephan C Schäfer ${ }^{1,5}$, Maxime Pellegrin ${ }^{2,5}$, Caroline Wyss ${ }^{3}$, Jean-François Aubert ${ }^{2}$, Jürg Nussberger ${ }^{2}$, \\ Daniel Hayoz ${ }^{4}$, Hans-Anton Lehr ${ }^{3}$ and Lucia Mazzolai ${ }^{2}$
}

It is known that hypertension is associated with endothelial dysfunction and that Angiotensin II (Ang II) is a key player in the pathogenesis of hypertension. We aimed to elucidate whether endothelial dysfunction is a specific feature of Ang II-mediated hypertension or a common finding of hypertension, independently of underlying etiology. We studied endothelial-dependent vasorelaxation in precapillary resistance arterioles and in various large-caliber conductance arteries in wild-type mice with Ang II-dependent hypertension (2-kidney 1-clip (2K1C) model) or Ang II-independent (volume overload) hypertension (1-kidney 1-clip model (1K1C)). Normotensive sham mice were used as controls. Aortic mechanical properties were also evaluated. Intravital microscopy of precapillary arterioles revealed a significantly impaired endothelium-dependent vasorelaxation in $2 \mathrm{~K} 1 \mathrm{C}$ mice compared with sham mice, as quantified by the ratio of acetylcholine (ACh)-induced over S-nitroso- $\mathrm{N}$-acetyl-D,Lpenicillamine (SNAP)-induced vasorelaxation (2K1C: $0.49 \pm 0.12$ vs. sham: $0.87 \pm 0.11, P=0.018$ ). In contrast, the $\mathrm{ACh} /$ SNAP ratio in volume-overload hypertension $1 \mathrm{~K} 1 \mathrm{C}$ mice was not significantly different from sham mice, indicating no specific endothelial dysfunction (1K1C: $0.77 \pm 0.27$ vs. sham: $0.87 \pm 0.11, P=0.138$ ). Mechanical aortic wall properties and endothelium-dependent vasorelaxation, assessed ex vivo in rings of large-caliber conductance (abdominal and thoracic aorta, carotid and femoral arteries), were not different between $2 \mathrm{~K} 1 \mathrm{C}, 1 \mathrm{~K} 1 \mathrm{C}$ and sham mice. Endothelial dysfunction is an early feature of Ang II- but not volume-overload-mediated hypertension. This occurs exclusively at the level of precapillary arterioles and not in conduit arteries. Our findings, if confirmed in clinical studies, will provide a better understanding of the pathophysiological mechanisms of hypertension.

Hypertension Research (2012) 35, 855-861; doi:10.1038/hr.2012.58; published online 10 May 2012

Keywords: angiotensin II; conductance vessels; endothelial-dependent vasorelaxation; resistance arterioles

\section{INTRODUCTION}

Hypertension has been associated with endothelial dysfunction, an important mechanism in clinical cardiovascular disease development and progression. ${ }^{1}$ Endothelial dysfunction, characterized by impaired endothelium-dependent vasorelaxation, has been documented in different vascular beds in both hypertensive patients ${ }^{2-5}$ and various animal models. ${ }^{6-12}$ Angiotensin II (Ang II), the effector peptide of the renin-angiotensin system (RAS), is one of the key participants in the pathogenesis of hypertension. Ang II-induced hypertension has a critical role in cardiovascular diseases via hemodynamic-dependent and -independent effects and contributes importantly to changes in vascular structure and function. ${ }^{13-15}$ One of the most frequently claimed negative effects of Ang II-induced hypertension is impaired endothelial function. In fact, several studies have shown that Ang II- induced hypertension contributes to aortic, carotid, coronary and mesenteric endothelial dysfunction. ${ }^{16-21}$ However, whether endothelial dysfunction is a specific feature of Ang II-mediated hypertension or a common finding of hypertension independently of the underlying etiology remains to be clarified. In addition to endothelial dysfunction, hypertension may also result in changes in the mechanical properties of the arterial wall. However, controversies still exist concerning a clear association between hypertension, Ang II and altered vascular mechanical properties. ${ }^{22-32}$ Chronic Ang II infusion does not appear to alter aortic compliance ${ }^{22}$ in animals. However, Ang II AT1 receptor blockade decreases the aortic and carotid stiffness in hypertensive patients, ${ }^{24,25}$ suggesting a possible direct role of Ang II in arterial mechanical property modulation. On the basis of these premises, the aim of the present study was to

${ }^{1}$ Institute of Pathology, Inselspital, University of Bern, Bern, Switzerland; ${ }^{2}$ Service of Angiology, University Hospital of Lausanne (CHUV), Lausanne, Switzerland; ${ }^{3}$ Institute of Pathology, University Hospital of Lausanne (CHUV), Lausanne, Switzerland and ${ }^{4}$ Department of Internal Medicine, Hôpital Cantonal, Fribourg, Switzerland

${ }^{5}$ These authors contributed equally to this work

Correspondence: Professor H-A Lehr, Institute of Pathology, University Hospital of Lausanne (CHUV), Lausanne, Switzerland.

E-mail: Hans-Anton.Lehr@chuv.ch

Received 11 September 2011; revised 23 January 2012; accepted 17 February 2012; published online 10 May 2012 
investigate the effects of Ang II-mediated vs. non-Ang II-mediated hypertension on endothelial function and on the mechanical properties of the arterial wall. For this purpose, wild-type (WT) mice with either Ang II-dependent (2-kidney 1-clip, 2K1C) or Ang IIindependent (1-kidney 1-clip, 1K1C) hypertension were used. ${ }^{33}$ Both large-caliber conductance arteries (aorta, carotid and femoral arteries) and small-sized resistance (precapillary arterioles) were considered for endothelial function assessment.

\section{METHODS}

\section{Mouse models of renovascular hypertension}

The experiments were approved by the local Institutional Animal Committee. Wild-type mice (Charles River Laboratories, L'Arbresle Cedex, L'Arbresle, France) were housed at $22^{\circ} \mathrm{C}$ with a $12: 12 \mathrm{~h}$ day-night cycle, fed regular rodent chow and given access to water ad libitum throughout the study. Two models of renovascular hypertension were generated, as previously described: (i) the renin-dependent Ang II-mediated 2-kidney 1-clip model (2K1C) and (ii) the renin-independent (volume overload) 1-kidney 1-clip model (1K1C). ${ }^{33}$ Because of their slightly higher body weight at the age of 14-16 weeks (26-32 g, affording increased comfort with the dorsal skinfold chambers), we chose to use only male mice for our experiments. Briefly, mice were anesthetized by isoflurane inhalation (1-2\% in oxygen), the left kidney was surgically exposed and the left renal artery was clipped to reduce renal perfusion. In the $1 \mathrm{~K} 1 \mathrm{C}$ model, right nephrectomy was performed in addition to clipping of the left renal artery. Non-clipped and non-nephrectomized wildtype mice were used as sham controls.

\section{Blood pressure, heart rate and hormone measurements}

Four weeks after renal artery clipping, the mean arterial blood pressure (MBP), heart rate and plasma renin were measured as previously described. ${ }^{33,34}$ For this purpose, the left carotid artery was cannulated with a polyethylene catheter and connected to a pressure transducer. Thirty minutes after anesthesia recovery, mean arterial blood pressure and heart rate were recorded in awake mice. The plasma renin concentration (PRC) and plasma renin activity (PRA) were determined as previously described, using a modified microassay based on an angiotensin trapping method. ${ }^{34}$

In vivo assessment of endothelial function in the microcirculation The skinfold chamber model allows the investigation, in non-anesthetized animals, of nutritional capillary perfusion, as well as of pre- and post-capillary microvessels, in fine, striated skin muscle. ${ }^{35}$ Four weeks after the induction of arterial hypertension, male mice (18-20 weeks old) were anesthetized with xylazine and ketamine (10 $\mathrm{mg} \mathrm{kg}^{-1}$ and $100 \mathrm{mg} \mathrm{kg}^{-1}$, respectively). Observation chambers were implanted into the dorsal skin fold as previously described..$^{35,36}$ Two days after chamber implantation, the tissue within the observation chambers was examined at scanning magnification for signs of inflammation (increased microvessel tortuosity and reduced blood-cell velocity), edema (incapacity to focus on microvessel edges) or flow obstruction (venous or venular dilation), and those animals in which any signs of microcirculatory compromise were noted were excluded from further experimentation. To reliably eliminate any experimentation bias, this exclusion of animals from the study based on the examination of the observation chambers was performed without any knowledge of the group assignments of the mice. The percentage of acceptable chambers compared well with prior experience in C57/BL6, Balbc, hairless, nude or ApoE ko mice. Intravital microscopic experiments were performed according to previously published protocols. ${ }^{36,38}$ To study endothelial function, the same blood vessel segments were first observed after 5-min superfusion periods with acetylcholine $(\mathrm{ACh})$ in a dose-dependent manner (ACh, $0.1-10 \mu \mathrm{moll}^{-1}$ ) to test endothelium-dependent, nitric-oxide (NO)-mediated vasorelaxation. Second, after a 10-min recovery period, a 5-min superfusion period with the exogenous NO-donor S-nitroso- $N$-acetyl-D,L-penicillamine (SNAP, $10 \mu \mathrm{moll}^{-1}$ ), inducing maximal endothelium-independent, NO-mediated vasorelaxation, was studied. For the quantification of the intravital microscopic findings, still video images were imported using the S-VHS port of a Macintosh computer (Power PC G4; Mac OS X; Apple Computer; Cupertino, CA, USA) equipped with a built-in graphic capture board using the acquire command within Photoshop (Photoshop 7.0; Adobe Systems; San Jose, CA, USA). Microvessel diameters were assessed using Photoshop-based image analysis as described previously. ${ }^{39}$ At the end of the experiments, the tissues contained within the observation window were removed and fixed in $4 \%$ buffered formaldehyde, and 4- $\mu \mathrm{m}$ sections were stained with hematoxylin and eosin and Elastica van Giesson according to standard protocols.

\section{Ex vivo assessment of endothelial function in conduit arteries}

The thoracic and abdominal aortas and the carotid and femoral arteries were removed from male and female mice, and carefully cleaned of adhering adipose and fibrous tissue. Subsequently, complete transverse rings of $2 \mathrm{~mm}$ length were cut for ex vivo reactivity experiments using a modified Mulvany setup. Each ring was suspended between wires attached to force transducers in a Multi Myograph System (Model 610M) and incubated in warm $\left(37^{\circ} \mathrm{C}\right)$ Krebs solution $\left(118 \mathrm{mmoll}^{-1} \mathrm{NaCl}, 4.65 \mathrm{mmoll}^{-1} \mathrm{KCl}, 2.5 \mathrm{mmoll}^{-1} \mathrm{CaCl}_{2}\right.$, $1.18 \mathrm{mmoll}^{-1} \quad \mathrm{KH}_{2} \mathrm{PO}_{4}, 24.9 \mathrm{mmoll}^{-1} \mathrm{NaHCO}_{3}, 1.18 \mathrm{mmoll}^{-1} \mathrm{MgSO}_{4}$, $12 \mathrm{mmoll}^{-1}$ glucose, $\mathrm{pH}$ 7.4) bubbled with $95 \% \mathrm{O}_{2}-5 \% \mathrm{CO}_{2}$. The system was allowed to stabilize for $60 \mathrm{~min}$ at $3-4 \mathrm{mN}$ optimal resting tension. First, we studied the concentration-dependent contraction in response to phenylephrine (Phe; $\left.10^{-9}-10^{-5} \mathrm{moll}^{-1}\right)$. The vasorelaxation responses to ACh $\left(3 \times 10^{-8}\right.$ $10^{-5} \mathrm{moll}^{-1}, 3 \times 10^{-8}-10^{-6} \mathrm{moll}^{-1}, 10^{-9}-10^{-7} \mathrm{moll}^{-1}$ and $10^{-9}-3 \times 10^{-5}$ $\mathrm{mol} / \mathrm{l}$ for the thoracic aorta, abdominal aorta, carotid artery and femoral artery, respectively) and to the NO donor sodium nitroprusside (SNP; $10^{-9}$ to $10^{-5} \mathrm{moll}^{-1}$ ) were then assessed as previously described. ${ }^{40}$ The degree of vasodilation was expressed as a percentage reduction of isotonic tension from the precontracted state as induced by $10^{-5} \mathrm{moll}^{-1}$ phenylephrine.

\section{In vivo assessment of vessel wall mechanical properties}

Compliance and distensibility were measured in isoflurane-anesthetized mice. An A-mode ultrasonic echo-tracking device (NIUS 02, Asulab SA, Neuchatel, Switzerland) was used as previously described. ${ }^{41-43}$ Briefly, a $10-\mathrm{MHz}$ piezoelectric transducer was positioned perpendicular to the abdominal aorta. Doppler guidance was used to ensure correct vertical positioning of the probe, which was set to A-mode (radio-frequency echo line). The ultrasonic echoes reflected by the interfaces between the blood and both anterior and posterior walls were sampled at $100 \mathrm{MHz}$ and stored at $500 \mathrm{~Hz}$ repetition frequency. The vascular and media-adventitia interfaces were subsequently selected by the operator on the radio-frequency echo line and automatically tracked to obtain the vessel diameter and its variation over time. The built-in post-processing allows the immediate calculation of the diameterpressure relationship from the simultaneous arterial diameter and blood pressure measurements stored at $50 \mathrm{~Hz}$. This diameter-pressure relationship is subsequently converted into cross-sectional compliance- and distensibilitypressure curves. Cross-sectional compliance $(C)$ is expressed by $C=\Delta S / \Delta P$, where $\Delta S$ is the change in cross-section of the lumen and $\Delta P$ the change in blood pressure. Arterial cross-sectional distensibility is the compliance value normalized for the cross-section. Distensibility $(D)$ is the compliance value normalized by the cross-section $(S)$ and is expressed as $D=(1 / S) \mathrm{x} \Delta S / \Delta P$

\section{Statistical analysis}

The distribution was found to be non-normal, which implies that a nonparametric test had to be used. We used the Mann-Whitney $U$-test to compare the results obtained in the two distinct experimental groups and the sham group (results in Figures 1 and 2), whereas the two-way repeatedmeasures ANOVA and Bonferroni post hoc tests are used to analyze the doseresponse relationships (Figure 4). All of the data are expressed as the mean \pm s.e.m. For statistical analysis, we used the GraphPad Prism software. All of the statistical tests were two-sided, and $P$ values $<0.05$ were considered to be statistically significant.

\section{RESULTS}

The hemodynamic and plasma renin measurements are summarized in Table 1 . Both $2 \mathrm{~K} 1 \mathrm{C}$ and $1 \mathrm{~K} 1 \mathrm{C}$ mice developed significant 


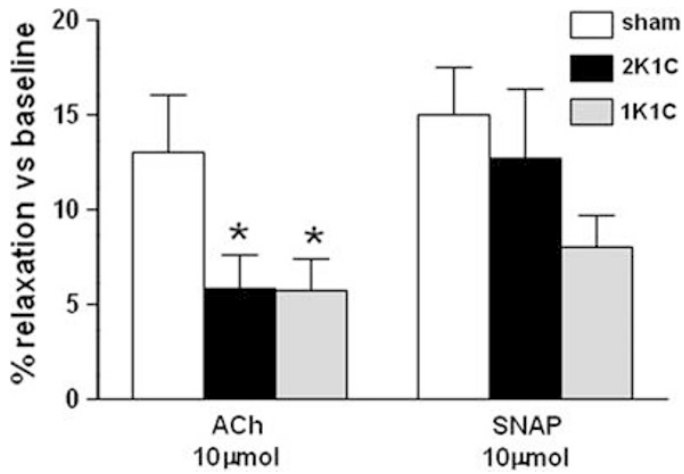

Figure 1 Endothelium-dependent vasorelaxation of the precapillary resistance arterioles as assessed by intravital microscopy. Mice were chronically instrumented with dorsal skinfold chambers, allowing the in vivo investigation of the precapillary resistance arterioles (20-60 $\mu \mathrm{m}$ in diameter) and their response to acetycholine (ACh) and SNAP superfusion. The bar graph shows the diameter variations following endothelium-dependent, NO-mediated vasorelaxation and maximal endothelium-independent, SNAP compared with the untreated baseline diameter. The data are expressed as the mean \pm s.e.m.; $6-10$ vessels were assessed in each animal; $n=6-7$ mice per group. ${ }^{*} P<0.05$ vs. sham group (non-parametric Mann-Whitney $U$-test).

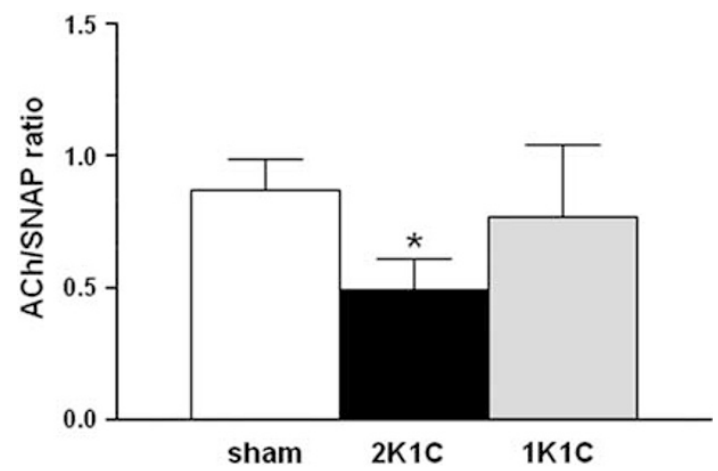

Figure 2 Acetylcholine (ACh)/S-nitroso- $N$-acetyl-D,L-penicillamine ratios. The ACh/SNAP ratio represents a meaningful indicator of endothelial function. The ACh/SNAP ratio is preserved in 1-kidney 1 -clip model (1K1C) mice, whereas this value is significantly decreased in 2-kidney 1-clip model (2K1C) compared with sham mice, indicating endothelial dysfunction. The data are expressed as the mean \pm s.e.m.; $n=6-7$ mice per group. ${ }^{*} P<0.05$ vs. sham group (non-parametric Mann-Whitney U-test).

hypertension (animals with a blood pressure below $130 \mathrm{mmHg}$ were excluded from the study). As expected, plasma renin activity and plasma renin concentration were significantly increased in hypertensive $2 \mathrm{~K} 1 \mathrm{C}$ mice (Ang II-dependent hypertension) compared with hypertensive 1K1C (volume-overload-dependent hypertension) and normotensive sham animals. The heart rate was similar in all groups.

\section{Ang II-mediated hypertension induces endothelial dysfunction in} precapillary resistance arterioles

Out of a total of $n=34$ hypertensive or sham-operated mice with successfully implanted dorsal skinfold chambers, $n=15$ were excluded from the study because of perioperative death, blurred microscopic images due to edema formation, or bleeding during the intravital microscopic examination. Endothelial dysfunction is defined as reduced vasorelaxation in response to ACh in the presence of a normal response to SNAP. ${ }^{44}$ Intravital microscopy of the precapillary resistance arterioles showed significantly impaired AChinduced vasorelaxation $\left(10 \mu \mathrm{moll}^{-1}\right)$ in the hypertensive $2 \mathrm{~K} 1 \mathrm{C}$ mice compared with the normotensive sham animals $(5.9 \pm 1.7 \%$ in $2 \mathrm{~K} 1 \mathrm{C}$ vs. $13.0 \pm 3.1 \%$ in sham mice; $P=0.035$; Figure 1$)$. ACh-induced vasorelaxation was also significantly reduced in the hypertensive $1 \mathrm{~K} 1 \mathrm{C}$ mice in comparison with the normotensive sham animals $(5.8 \pm 1.6 \%$ vs. $13.0 \pm 3.1 \%$ in sham mice; $P=0.014$; Figure 1 ). The extent of ACh-induced vasorelaxation impairment was comparable between $2 \mathrm{~K} 1 \mathrm{C}$ and $1 \mathrm{~K} 1 \mathrm{C}$ mice. SNAP-induced vasorelaxation $\left(10 \mu \mathrm{moll}^{-1}\right)$ showed no statistically significant differences between groups. However, a $50 \%$ reduction of SNAP-induced vasorelaxation in the hypertensive $1 \mathrm{~K} 1 \mathrm{C}$ mice was observed compared with the sham normotensive mice $(8.0 \pm 1.6 \%$ in $1 \mathrm{~K} 1 \mathrm{C} v$ s. $15 \pm 2.5 \%$ in sham mice; $P=0.051$, Figure 1).

The ratio of ACh-induced to SNAP-induced vasorelaxation is a meaningful indicator of endothelial function. This ratio determines the degree of endothelium-dependent and NO-mediated vasorelaxation, compared with the maximal NO-mediated vasorelaxation capacity, in a vessel segment with a physiologically predetermined baseline diameter. In $2 \mathrm{~K} 1 \mathrm{C}$ mice, the ACh/SNAP ratio was significantly reduced by $44 \%$ compared with sham mice $(0.49 \pm 0.12$ in 2K1C vs. $0.87 \pm 0.11$ in sham mice, $P=0.018$; Figure 2), indicating impaired endothelial function. In contrast, the ACh/SNAP ratio in the $1 \mathrm{~K} 1 \mathrm{C}$ mice showed only a slight, insignificant reduction $(0.77 \pm 0.27$ in $1 \mathrm{~K} 1 \mathrm{C}$ vs. $0.87 \pm 0.11$ in sham mice; $P=0.138$; Figure 2 ). Histological analysis of the microvessels within the observation windows showed no remodeling of the vascular or perivascular tissues in any group of mice (Figure 3). Please note that the endothelial cell layer is intact in all of the animals and shows no histomorphological abnormalities (Figures 3d-f).

Ang II-mediated and Ang II-independent hypertension do not alter endothelial function in conductance arteries

No differences were found in the concentration-contractile response induced by Phe in the thoracic aortas, abdominal aortas, carotid arteries or femoral arteries in any experimental groups. In particular, no differences in the concentration-response curves to the endothelium-dependent vasodilator ACh were observed among the sham, $2 \mathrm{~K} 1 \mathrm{C}$ and $1 \mathrm{~K} 1 \mathrm{C}$ mice (Figure 4). Finally, the endothelium-independent responses to sodium nitroprusside were similar in all of the experimental groups (data not shown). We would like to emphasize that we found no differences in endothelium-dependent relaxation in the conductance vessels between female and male mice (data not shown).

Ang II-mediated hypertension does not affect the mechanical properties of the abdominal aorta

In vivo measurements showed no differences in aortic distensibility and compliance among the sham, 2K1C and 1K1C mice (Figure 5). The internal diameter and aorta wall thickness did not differ among all of the experimental groups (data not shown).

\section{DISCUSSION}

In this study, we show that in the early stages of hypertension only Ang II-mediated hypertension induces endothelial dysfunction, and that this dysfunction occurs exclusively at the level of the precapillary arterioles and not in conduit arteries. No significant differences were observed in terms of mechanical vascular wall properties in hypertensive vs. normotensive mice. Contrary to previous studies that infused Ang II in rats ${ }^{16-21}$ inducing a significant reduction in 

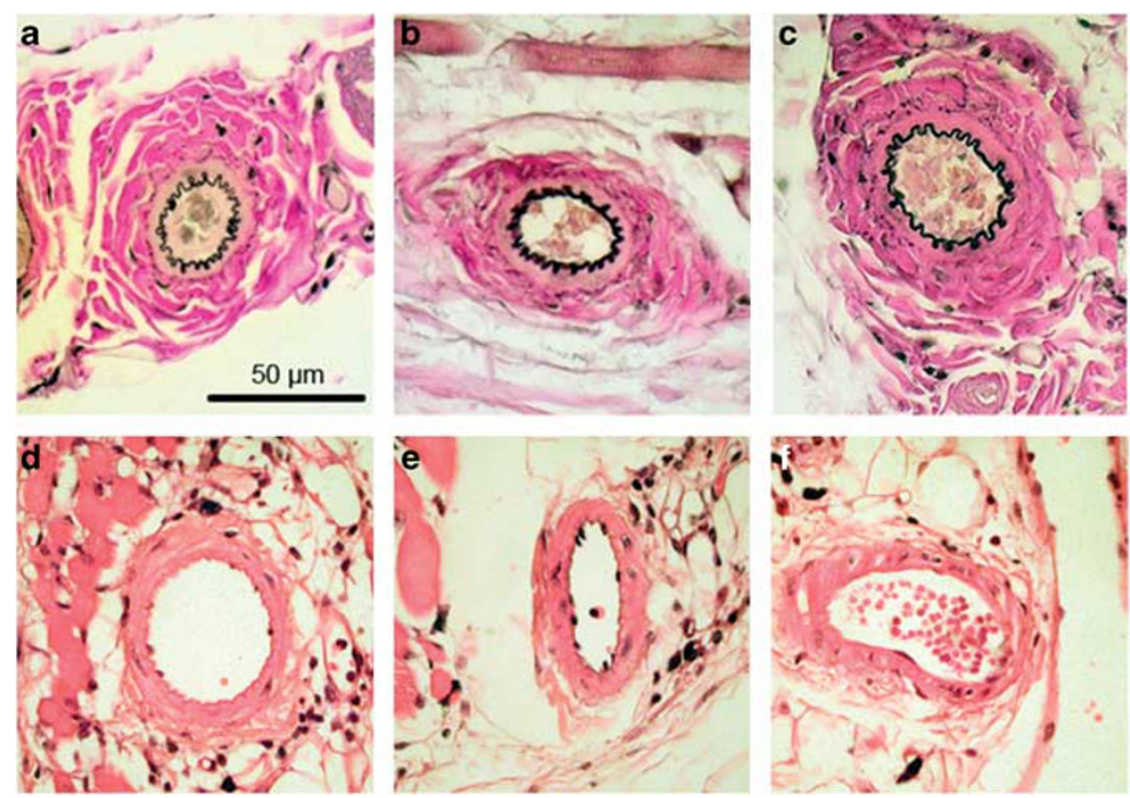

Figure 3 Representative histological images of resistance arterioles from within the observation window of normotensive sham and hypertensive mice. The upper panels show standard elastica Van Giesson stains, and the lower panels show hematoxylin and eosin stains: normotensive sham mice (a, d); hypertensive $2 \mathrm{~K} 1 \mathrm{C}$ mice (b, e); hypertensive $1 \mathrm{~K} 1 \mathrm{C}$ mice (c, f). The scale bar corresponds to a length of $50 \mu \mathrm{m}$.

Table 1 Hemodynamic and hormonal parameters in sham, 2K1C and 1K1C WT mice

\begin{tabular}{lllcc}
\hline & MBP (mm Hg) & HR (bpm) & PRA $\left(n g m l^{-1} h^{-1}\right)$ & $P R C\left(n g m l^{-1} h^{-1}\right)$ \\
\hline Sham & $116 \pm 3$ & $647 \pm 23$ & $5.7 \pm 1$ & $847 \pm 83$ \\
2 K1C & $144 \pm 5^{* *}$ & $655 \pm 13$ & $17.6 \pm 6.7^{\#}$ & $1887 \pm 596^{\#}$ \\
1 K1C & $152 \pm 4^{* * *}$ & $656 \pm 9$ & $5.3 \pm 0.8$ & $614 \pm 86$ \\
\hline
\end{tabular}

Abbreviations: HR, heart rate; MBP, mean blood pressure; PRA, plasma renin activity; PRC: plasma renin concentration; 2K1C, 2-kidney 1-clip model; 1K1C, 1-kidney 1-clip model; WT, wild type.

$n=6-12$ mice per group. ${ }^{* *} P<0.01,{ }^{* * *} P<0.001$ vs. sham, ${ }^{\#} P<0.05$ vs. sham and 1 K1.C.

endothelium-dependent vasorelaxation, we found no evidence for impaired endothelial function in large conductance arteries ex vivo. This discrepancy may be due to the different experimental models used. Indeed, renin-angiotensin system stimulation elicited by renal hypoperfusion, as it occurs in our $2 \mathrm{~K} 1 \mathrm{C}$ model, mimics the physiological pathway found in humans more perfectly than direct Ang II injection. ${ }^{16-21}$ Consistent with our findings, Arruda and coworkers found impaired endothelial function in the mesenteric arteriolar bed in $2 \mathrm{~K} 1 \mathrm{C}$ mice. ${ }^{45}$ In volume overload $1 \mathrm{~K} 1 \mathrm{C}$ hypertensive mice, both endothelium-dependent and -independent vasorelaxation decreased in the resistance arterioles compared with control normotensive mice. As a consequence, the ratio of ACh- over SNAP-induced vasorelaxation remained unchanged compared with normotensive mice, indicating no specific endothelial dysfunction. We speculate that in this model of volume-overload-induced hypertension, the impaired response to SNAP may be due to preexisting arteriolar dilation by the excessive blood volume, limiting SNAP-induced maximal NO-mediated vasorelaxation.

No differences in compliance or arterial distensibility in the abdominal aorta could be demonstrated in vivo. Histological sections of pre-capillary arterioles showed no alterations that could have pointed toward a morphological arterial 'stiffening.' Previous work from our group $^{43}$ showed that the mechanical properties of the arterial wall were modified only after 9 weeks of renal artery clipping in rats. This finding suggests that Ang II-induced arterial stiffness does not occur during the early stages of hypertension (4 weeks in our experiments) but is a feature of long-term hypertensive disease. In accordance with our results, previous studies have demonstrated that chronic Ang II infusion (14-28 days) did not alter aortic compliance in animals. ${ }^{22}$

Our data indicate that endothelial dysfunction in Ang II-mediated hypertension occurs preferentially in the resistance arteries rather than in the conductance arteries during the early stages of the disease. Well-known anatomical and physiological differences exist between conduit vessels and small precapillary 'effector' arterioles. Moreover, pulsed perfusion is present at the level of the conductance vessels, generating different responses in terms of endothelial NO synthesis, protein phosphorylation and oxidative stress signaling compared with constant flow as observed at the level of the resistance arterioles, such as those investigated in the present study. ${ }^{4-48}$ A portion of the systolic pressure is lost at the level of the resistance vessels because this segment of the cardiovascular tree transforms systemic blood pressure into nutritional microvascular tissue perfusion. It is therefore not surprising that Ang II-induced hypertension should manifest itself at this level and not at the level of conductance vessels. The difference in endothelial dysfunction between the various segments of the cardiovascular tree awaits further investigation.

This study had several limitations. The number of animals that were studied in this experiment was defined by the authors' experience with microvascular experimentation (characterized by high intra- and inter-individual variation of microvascular blood flow regulation) and the dorsal skinfold chamber model (which requires the stringent exclusion of animals that do not fulfill strict criteria of an intact microcirculation, see the Methods section). Needless to say, the authors would have liked to have used a higher number of animals into the final analysis. However, we believe that the statistical significance between the experimental groups reflects a biologically relevant observation. In this context, it should be noted that the decision to exclude animals from the microcirculatory 

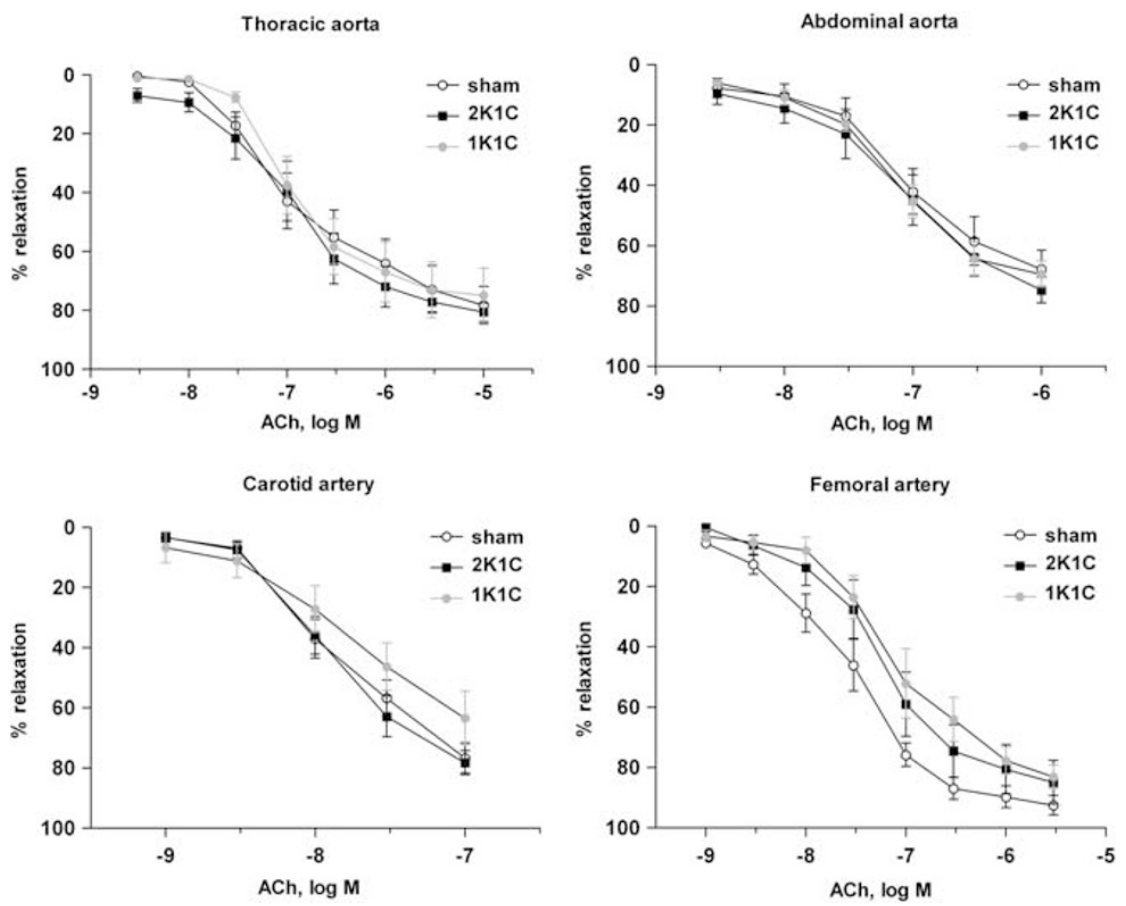

Figure 4 Endothelial function in conduit arteries. Endothelium-dependent vasorelaxation was studied ex vivo on rings of explanted thoracic aorta, abdominal aorta, carotid artery and femoral artery of mice with Ang II- (2K1C; black-filled squares) or volume-overload (1K1C; gray-filled circles)-induced hypertension. Normotensive sham mice were used as controls (empty circles). The data are expressed as the mean values \pm s.e.m.; $n=6-10$ mice per group. No statistically significant differences were observed among the groups (two-way repeated-measures analysis of variance test with post-hoc Bonferroni correction). The numbers of male/female animals examined for the thoracic, abdominal, carotid and femoral arteries were 7-4-3/0-3-3, 4-6-5/3-0-1, 5-7-5/ 2-0-1 and 3-4-6/3-2-0 (sham, 1-kidney 1-clip model (1K1C), 2-kidney 1-clip model (2K1C) groups), respectively. No significant differences were identified between male and female mice in any of the vascular segments (not shown).
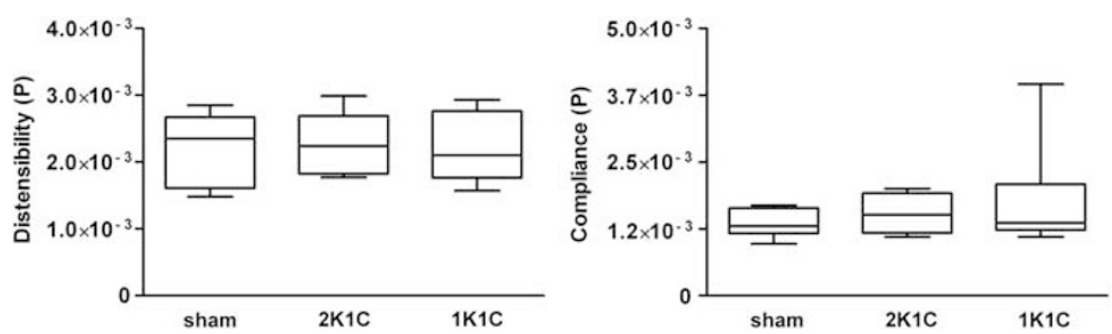

Figure 5 Parameters of arterial stiffness: Distensibility (left panel) and compliance (right panel) were measured in the abdominal aorta in vivo in $2 \mathrm{~K} 1 \mathrm{C}$ and $1 \mathrm{~K} 1 \mathrm{C}$ mice. Normotensive sham mice were used as controls. The data are expressed as the mean values \pm s.e.m.; $n=6-10$ mice per group. No statistically significant differences were observed among the groups (2-way repeated-measures ANOVA test with post-hoc Bonferroni correction).

experiments was made without any information on the group assignment of the animals, and hence a potential unconscious experimentation bias can be excluded. Another point that deserves to be scrutinized is the selection of the cutaneous microcirculation for our studies. The cutaneous microcirculation is a crucial player in thermoregulation and is only partially involved in systemic vascular resistance. However, other authors have demonstrated impaired endothelium-dependent vasodilation in the cutaneous microcirculation of patients with primary hypertension (reviewed in ref. 49), suggesting that cutaneous microcirculation may indeed participate in the pathogenesis of the disease. A third point should be discussed pertaining to the use of the $1 \mathrm{~K} 1 \mathrm{C}$ mouse model to study reninindependent volume-overload effects. Renin and Ang II synthesis increase in the acute phase following renal clipping, effecting a rapid rise in the blood pressure necessary to maintain adequate renal perfusion and assure kidney viability. However, volume overload, due to the inability to increase diuresis in the contralateral nephrectomized kidney, rapidly shuts off renin secretion in the clipped kidney. These events take place very rapidly, within a few hours after renal artery constriction. At the time when the $1 \mathrm{~K} 1 \mathrm{C}$ model was characterized in our laboratory, we measured the PRC over time after clipping: the plasma renin concentration increased within $5 \mathrm{~h}$ after clipping $\left(1918 \pm 302 \mathrm{ng} \mathrm{ml}^{-1} \mathrm{~h}^{-1}\right)$, returning to below-normal levels within $24 \mathrm{~h}$ after clipping $\left(392 \pm 85 \mathrm{ng} \mathrm{ml}^{-1} \mathrm{~h}^{-1}, P<0.05\right.$ vs. $5 \mathrm{~h}$ ) (unpublished data). The values remained normal/low thereafter. These observations are consistent with published data. ${ }^{50}$ In addition, previous studies from our laboratory have shown that the renin mRNA levels in the clipped left kidneys of $1 \mathrm{~K} 1 \mathrm{C}$ mice were comparable to the renin mRNA levels found in the non-clipped kidneys of control rats. ${ }^{33}$ On the basis of these considerations, we 
chose to allow sufficient time between the clipping procedure and the micro- and macrocirculatory experiments in our study (4 weeks). With this safety measure, we have come to believe that the $1 \mathrm{~K} 1 \mathrm{C}$ mouse model can be safely and correctly used as a relevant model to investigate the specific effects of renin-independent, volume-overloaddependent hypertension.

In conclusion, the results presented herein shed light on the association between hypertension and endothelial dysfunction. This study identifies impaired endothelial function in resistance arterioles as a feature of early Ang II-mediated hypertension. These findings, if confirmed in hypertensive patients, will provide a better knowledge of the pathophysiological mechanisms underlying this disease.

\section{CONFLICT OF INTEREST}

The authors declare no conflicts of interest.

\section{ACKNOWLEDGEMENTS}

We thank Irène Keller and Susana Leuba for their excellent technical assistance. This work was supported by the Swiss National Science Foundation (grant 3200BO-109900).

1 Landmesser U, Drexler H. Endothelial function and hypertension. Curr Opin Cardiol 2007; 22: 316-320.

2 Higashi Y, Oshima T, Ozono R, Matsuura H, Kajiyama G. Aging and severity of hypertension attenuate endothelium-dependent renal vascular relaxation in humans. Hypertension 1997; 30: 252-258.

3 Hamasaki S, Al Suwaidi J, Higano ST, Miyauchi K, Holmes Jr DR, Lerman A. Attenuated coronary flow reserve and vascular remodeling in patients with hypertension and left ventricular hypertrophy. J Am Coll Cardiol 2000; 35: 1654-1660.

4 Ward NC, Croft KD, Hodgson J, Rich L, Beilin LJ, Puddey IB. Brachial artery vasomotor function is inversely associated with $24-h$ ambulatory blood pressure. J Hypertens 2004; 22: 967-972.

5 Sainsbury CA, Coleman J, Brady AJ, Connell JM, Hillier C, Petrie JR. Endotheliumdependent relaxation is resistant to inhibition of nitric oxide synthesis, but sensitive to blockade of calcium-avtivated potassium channels in essential hypertension. J Hum Hypertens 2007; 21: 808-814.

6 Bauersachs J, Bouloumié A, Mülsch A, Wiemer G, Fleming I. Busse. Vasodilator dysfunction in aged spontaneously hypertensive rats: changes in NO synthase III and soluble guanylyl cyclase expression, and in superoxide anion production. Cardiovasc Res 1998; 37: 772-779.

7 Sunano S, Watanabe H, Tanaka S, Sekiguchi F, Shimamura K. Endothelium-derived relaxing, contracting and hyperpolarizing factors of mesenteric arteries of hypertensive and normotensive rats. Br J Pharmacol 1999; 126: 709-716.

8 Somers MJ, Mavromatis K, Galis ZS, Harrison DG. Vascular superoxide production and vasomotor function in hypertension induced by deoxycorticosterone acetate-salt. Circulation 2000; 101: 1722-1728.

9 Sekiguchi F, Yamamoto K, Matsuda K, Kawata K, Negishi M, Shinomiya K, Shimamur $\mathrm{K}$, Sunano S. Endothelium-dependent relaxation in pulmonary arteries of L-NAMEtreated Wistar and stroke-prone spontaneously hypertensive rats. J Smooth Muscle Res 2002; 38: 131-144.

10 Touyz RM, Deschepper C, Park JB, He G, Chen X, Neves MF, Virdis A, Schiffrin EL. Inhibition of mitogen-activated protein/extracellular signal-regulated kinase improves endothelial function and attenuates Ang II-induced contractility of mesenteric resistance arteries from spontaneously hypertensive rats. J Hypertens 2002; 20: 1053-1054.

11 De Gennaro Colonna V, Rigamonti A, Fioretti S, Bonomo S, Manfredi B, Ferrario P, Bianchi M, Berti F, Muller EE, Rossoni G. Angiotensin-converting enzyme inhibition and angiotensin AT1-receptor antagonism equally improve endothelial vasodilator function in L-NAME-induced hypertensive rats. Eur J Pharmacol 2005; 516: 253-259.

12 Lima VV, Giachini FR, Choi H, Carneiro FS, Carneiro ZN, Fortes ZB, Carvalho MH, Webb RC, Tostes RC. Impaired vasodilator activity in deoxycorticosterone acetate-salt hypertension is associated with increased protein O-GicNAcylation. Hypertension 2009; 53: 166-174.

13 Mazzolai L, Duchosal MA, Korber M, Bouzourene K, Aubert JF, Hao H, Vallet V, Brunner HR, Nussberger J, Gabbiani G, Hayoz D. Endogenous angiotensin II induces atherosclerotic plaque vulnerability and elicits a Th1 response in ApoE-/- mice. Hypertension 2004; 44: 277-282.

14 Schmieder RE, Hilgers KF, Schlaich MP, Schmidt BM. Renin-angiotensin system and cardiovascular risk. Lancet 2007; 369: 1208-1219.

15 Higuchi S, Ohtsu H, Suzuki H, Shirai H, Frank GD, Eguchi S. Angiotensin II signal transduction through the AT1 receptor: novel insights into mechanisms and pathophysiology. Clin Sci (Lond) 2007; 112: 417-428.
16 Rajagopalan S, Kurz S, Münzel T, Tarpey M, Freeman BA, Griendlin KK, Harrison DG. Angiotensin II-mediated hypertension in the rat increases vascular superoxide production via membrane NADH/NADPH oxidase activation. Contribution to alterations of vasomotor tone. J Clin Invest 1996; 97: 1916-1923.

17 Nakane H, Miller Jr FJ, Faraci FM, Toyoda K, Heistad DD. Gene transfer of endothelial nitric oxide synthase reduces angiotensin II-induced endothelial dysfunction. Hypertension 2000; 35: 595-601.

18 Virdis A, Neves MF, Amiri F, Touyz RM, Schiffrin EL. Role of NAD(P)H oxidase on vascular alterations in angiotensin II-infused mice. J Hypertens 2004; 22: 535-542.

19 Wölkart G, Stessel H, Brunner F. In vivo administration of D-arginine: effects on blood pressure and vascular function in angiotensin II-induced hypertensive rats. Atherosclerosis 2004; 176: 219-225.

20 Sarr M, Chataigneau M, Martins S, Schott C, El Bedoui J, Oak MH, Muller B, Chataigneau T, Schini-Kerth VB. Red wine polyphenols prevent angiotensin II-induced hypertension and endothelial dysfunction in rats: role of NADPH oxidase. Cardiovasc Res 2006; 71: 794-802.

21 Stec DE, Vera T, McLemore Jr GR, Kelsen S, Rimoldi JM, Gadepalli RS, Ryan MJ. Heme oxygenase-1 induction does not improve vascular relaxation in angiotensin II hypertensive mice. Am J Hypertens 2008; 21: 189-193.

22 Brouwers-Ceiler DL, Nelissen-Vrancken HJ, Smits JF, De Mey JG. The influence of angiotensin II-induced increase in aortic wall mass on compliance in rats in vivo. Cardiovasc Res 1997; 33: 478-484.

23 Fitch RM, Rutledge JC, Wang YX, Powers AF, Tseng JL, Clary T, Rubanyi GM Synergistic effect of angiotensin II and nitric oxide synthase inhibitor in increasing aortic stiffness in mice. Am J Physiol Heart Circ Physiol 2006; 290: H1190-H1198.

24 Mahmud A, Feely J. Effect of angiotensin ii receptor blockade on arterial stiffness: beyond blood pressure reduction. Am J Hypertens 2002; 15: 1092-1095.

25 Okura T, Watanabe S, Kurata M, Koresawa M, Irita J, Enomoto D, Jotoku M, Miyoshi K Fukuoka T, Higaki J. Long-term effects og angiotensin II receptor blockade with valsartan on carotid arterial stiffness and hemodynamic alterations in patients with essential hypertension. Clin Exp Hypertens 2008; 30: 415-422.

26 Simon P, Levenson J. Use of arterial compliance for evaluation of hypertension. Am J Hypert 1991; 4: 97-105.

27 Hayoz D, Rutschmann B, Perret F, Niederberger M, Tardy Y, Mooser V, Nussberger J, Waeber B, Brunner HR. Conduit artery compliance and distensibility are not necessarily reduced in hypertension. Hypertension 1992; 20: 1-6.

28 Laurent S, Hayoz D, Trazzi S, Boutouyrie P, Waeber B, Omboni S, Brunner HR, Mancia G, Safar M. Isobaric compliance of the radial artery is increased in patients with essential hypertension. J Hypertens 1993; 11: 89-93.

29 Longo D, Zaetta V, Perkovic D, Frezza P, Ragazzo F, Mos L, Santonastaso M, Garbelotto $R$, Benetos A, Palatini P. Impaired arterial elasticity in young patients with yhite-coat hypertension. Blood Press Monit 2006; 11: 243-249.

30 Stewart AD, Jiang B, Millasseau SC, Ritter JM, Chowienczyk PJ. Acute reduction of blood pressure by nitroglycerin does not normalize large artery stiffness in essenetial hypertension. Hypertension 2006; 48: 404-410.

31 Erdogan D, Caliskan M, Yildirim I, Gullu H, Baycan S, Ciftci O, Yildirir A, Muderrisoglu $\mathrm{H}$. Effects of normal blood pressure, prehypertension and hypertension on left ventricular diastolic function and aortic elastic properties. Blood Press 2007; 16 . $114-121$.

32 Kotchen TA, Kotchen JM, Grim CE, Krishnaswami S, Kidambi S. Aldosterone and alterations of hypertension-related vascular function in African Americans. Am Hypertens 2009; 22: 319-324.

33 Wiesel P, Mazzolai L, Nussberger J, Pedrazzini T. Two-kidney, one clip and one-kidney, one clip hypertension in mice. Hypertension 1997; 29: 1025-1030.

34 Nussberger J, Aubert JF, Bouzourene K, Pellegrin M, Hayoz D, Mazzolai L. Renin inhibition by aliskiren prevents atherosclerosis progression: comparison with irbesartan, atenolol, and amlodipine. Hypertension 2008; 51: 1306-1311.

35 Lehr HA, Leunig M, Menger MD, Nolte D, Messmer K. Dorsal skinfold chamber technique for intravital microscopy in nude mice. Am J Pathol 1993; 143: 1055-1062.

36 Schäfer SC, Wallerath T, Closs EI, Schmidt C, Schwarz PM, Förstermann U, Lehr HA Dexamethasone suppresses eNOS and CAT-1 and induces oxidative stress in mouse resistance arterioles. Am J Physiol Heart Circ Physiol 2005; 288: H436-H444.

37 de Wit C, Esser N, Lehr HA, Bolz SS, Pohl U. Pentobarbital-sensitive EDHF comediates ACh-induced arteriolar dilation in the hamster microcirculation. Am J Physiol 1999. 276: $\mathrm{H} 1527-\mathrm{H} 1534$.

38 allerath T, Witte K, Schäfer SC, Schwarz PM, Prellwitz W, Wohlfart P, Kleinert H, Lehr HA, Lemmer B, Förstermann U. Down-regulation of the expression of endothelial NO synthase is likely to contribute to glucocorticoid-mediated hypertension. Proc Natl Acad Sci USA 1999; 96: 13357-13362.

39 Brunner J, Krummenauer F, Lehr HA. Quantification of video-taped images in microcirculation research using inexpensive imaging software (Adobe Photoshop). Microcirculation 2000; 7: 103-107.

40 Pellegrin M, Alonso F, Aubert JF, Bouzourene K, Braunersreuther V, Mach F, Haefliger JA, Hayoz D, Berthelot A, Nussberger J, Laurant P, Mazzolai L. Swimming prevents vulnerable atherosclerotic plaque development in hypertensive 2-kidney, 1-clip mice by modulating angiotensin II type 1 receptor expression independently from hemodynamic changes. Hypertension 2009; 53: 782-789.

41 Tardy Y, Hayoz D, Mignot JP, Richard P, Brunner HR, Meister JJ. Dynamic non-invasive measurements of arterial diameter and wall thickness. J Hypertens 1992; 10: S105-S109.

42 Hayoz D, Tardy Y, Rutschmann B, Mignot JP, Achakri H, Feihl F, Meister JJ, Waeber B, Brunner HR. Spontaneous diameter oscillations of the radial artery in humans. $A m$ J Physiol 1993; 264: H2080-H2084. 
43 Zanchi A, Stergiopulos N, Brunner HR, Hayoz D. Differences in the mechanical properties of the rat carotid artery in vivo, in situ, and in vitro. Hypertension 1998; 32: $180-185$.

44 Li R, Wang WQ, Zhang H, Yang X, Fan Q, Christopher TA, Lopez BL, Tao L, Goldstein $\mathrm{BJ}$, Gao F, Ma XL. Adiponectin improves endothelial function in hyperlipidemic rats by reducing oxidative/nitrative stress and differential regulation of eNOS/iNOS activity. Am J Physiol Endocrinol Metab 2007; 293: E1703-E1708.

45 Arruda RMP, Peotta VA, Meyrelles SS, Vasquez EC. Evaluation of vascular function in apolipoprotein $\mathrm{E}$ knockout mice with Ang-dependent renovascular hypertension. Hypertension 2005; 46: 932-936.

46 Peng X, Haldar S, Deshpande S, Irani K, Kass DA. Wall stiffness suppresses Akt/eNOS and cytoprotection in pulse-perfused endothelium. Hypertension 2003; 41: 378-381.
47 Nakano T, Tominaga R, Nagano I, Okabe H, Yasui H. Pulsatile flow enhances endothelium-derived nitric oxide release in the peripheral vasculature. Am J Physiol Heart Circ Physiol 2000; 278: H1098-H1104.

48 Silacci P, Desgeorges A, Mazzolai L, Chambaz C, Hayoz D. Flow pulsatility is a critical determinant of oxidative stress in endothelial cells. Hypertension 2001; 38: 1162-1166.

49 Holowatz LA, Thompson-Torgerson CS, Kenney WL. The human cutaneous circulation as a model of generalized microvascular dysfunction. J Appl Physiol 2008; 105: 370-372.

50 Heo HJ, Yun MR, Jung KH, Lee JY, Park JY, Lee SJ, Bae SS, Lee WS, Kim CD. Endogenous angiotensin II enhances atherogenesis in apolipoprotein E-deficient mice with renovascular hypertension through activation of smooth muscle cells. Life Sci 2007; 80: 1057-1063. 